\title{
USO DE COBERTURA MORTA VEGETAL NO CONTROLE DA UMIDADE E TEMPERATURA DO SOLO, NA INCIDÊNCIA DE PLANTAS INVASORAS E NA PRODUÇÃO DA CENOURA EM CULTIVO DE VERÃO
}

\author{
Efficiency of mulching on soil moisture and temperature, \\ weed control and yield of carrot in summer season
}

\author{
Francisco Vilela Resende ${ }^{1}$, Luciano Soares de Souza ${ }^{2}$, Paulo Sérgio Rabello de Oliveira², Ronan Gualberto
}

RESUMO

Avaliaram-se os efeitos de diferentes tipos de cobertura morta de solo de origem vegetal sobre o crescimento, controle de plantas daninhas, produtividade e regime hidrotérmico do solo no cultivo da cenoura, cultivar Brasília, em um experimento conduzido no período de setembro a dezembro de 1998, em Marília, SP. O delineamento experimental utilizado foi o de blocos casualizados, com cinco tratamentos e quatro repetições em parcelas de $2 \mathrm{~m}^{2}$. Estudou-se os seguintes tipos de cobertura: serragem de madeira, casca de arroz, maravalha (raspa de madeira), capim seco (Cynodon spp.) e controle (solo sem cobertura morta). A utilização da cobertura morta de solo mostrou-se como uma prática vantajosa para o cultivo de verão da cenoura, reduziu a temperatura em até $3,5^{\circ} \mathrm{C}$, aumentou a retenção de umidade do solo em até $2,3 \%$ em relação ao controle e melhorou o desenvolvimento das plantas de cenoura. Houve menor incidência de plantas daninhas com o uso de maravalha e capim seco que, juntamente com a serragem também aumentaram o número de plantas colhidas. Entre os tipos de cobertura morta utilizados, a casca de arroz e a maravalha se destacaram em relação ao solo descoberto como os materiais que proporcionaram maior produtividade (112,6 e 99,6 t/ha respectivamente). O uso de cobertura morta de solo mostrou-se vantajoso em vários aspectos para cultura da cenoura, sendo técnica e economicamente viável, principalmente, em pequenas áreas e em cultivos orgânicos.

Termos para indexação: Daucus carota L., cobertura morta, plantas daninhas, produtividade.

\begin{abstract}
The effects of different mulches were evalueted on carrot culture, cultivar Brasilia, in a experiment carried out at Marilia, São Paulo State, Brazil, from september to december/1998. The experimental design was a randomized block with four replications and size plots of $2 \mathrm{~m}^{2}$. Wood dust, wood chips, dry grass (Cynodon spp.), rice straw and control (soil without cover) were tested and their effects on the soil hidrothermal regime, weed control, growth and yield of carrot were determined. Mulching materials showed better carrots plants development, mild soil temperature $\left(3,5^{\circ} \mathrm{C}\right.$ less control trait) and better soil moisture (2,3\% high control trait). Dry grass and wood chips showed lower weed infestation and dry grass, wood chips and wood dust increased carrot stand. Mulches with rice straw and wood increased carrot yield (112,6 e 99,6 t/ha respectively). Mulching use is technically and economically viable for carrot growing, mainly in small areas and in organic farms.
\end{abstract}

Index terms: Daucus carota L, mulching, weeds, yield.

(Recebido para publicação em $1^{\circ}$ de outubro de 2003 e aprovado em1º de julho de 2004)

\section{INTRODUÇÃO}

No Brasil, a cenoura (Daucus carota L.) é cultivada durante o ano todo, havendo cultivares específicas para o outono-inverno, primavera e verão. Entretanto, no cultivo de verão ocorrem uma série de intempéries climáticas que podem prejudicar, tanto a germinação das sementes como o desenvolvimento da planta e qualidade das raízes.

No verão também ocorre maior disponibilidade de água e altas temperaturas, favorecendo assim a ocorrência de plantas daninhas nas áreas de cultivo. A intensidade das interferências das plantas sobre a cultura da cenoura são medidas pelos efeitos negativos verificados so- bre a produtividade da cultura. As perdas na produção na cultura da cenoura, causadas pelas plantas daninhas variam de 39-50\% (WILLIAM e WARRE, 1975) e podem até mesmo chegar a 100\% (BLANCO e OLIVEIRA, 1971).

Estes fatores restritivos podem ser parcialmente amenizados com a utilização de cobertura de solo com filmes plásticos, materiais de origem vegetal e outros (PEREIRA et al., 2000). A cobertura do solo em hortaliças tem sido utilizada com o intuito de reduzir a desagregação do solo, incidência de plantas daninhas, além de contribuir para manutenção da temperatura e umidade do solo em níveis adequados para o desenvolvimento das plantas (MULLER, 1991). 
A utilização de cobertura morta de solo não é uma prática tradicional na cultura da cenoura, mas acredita-se que essa técnica possa ser vantajosa em pequenas áreas em função das condições de solo exigidas para o cultivo desta espécie, restando apenas analisar sua economicidade. Em sistemas de cultivo orgânico seu uso pode ser bastante vantajoso como forma de controle de plantas daninhas, devido às restrições de uso de produtos químicos neste sistema de cultivo.

As vantagens da cobertura morta na cenoura podem se estender desde a maximização da germinação das sementes, uma vez que esta espécie apresenta baixo poder germinativo (padrão nacional é de 65\%), até a manutenção das condições adequadas de temperatura e umidade de solo necessárias ao ótimo desenvolvimento das raízes.

Com o propósito de verificar os benefícios da cobertura morta de solo no desenvolvimento e produtividade da cenoura realizou-se este trabalho com diferentes materiais de origem vegetal (serragem de madeira, casca de arroz, raspa de madeira e capim seco), considerando-se para sua escolha a facilidade de aquisição e utilização pelo produtor.

\section{MATERIAL E MÉTODOS}

Este trabalho foi conduzido no período de verão no campo experimental da Faculdade de Ciências Agrárias da Universidade de Marília (UNIMAR), Marília SP, em um solo classificado como Podzólico Vermelho Amarelo que apresentou os seguintes valores para as características químicas: $\mathrm{pH}$ em $\mathrm{CaCl}_{2}$ : 6,2; matéria orgânica: 20,8 g.dm ${ }^{-3}$; P: $121 \mathrm{mg} \cdot \mathrm{dm}^{-3}$; K: 5,1 mmol ${ }_{\mathrm{c}} \cdot \mathrm{dm}^{-3}$; Ca: $43 \mathrm{mmol}_{\mathrm{c}} \cdot \mathrm{dm}^{-3}$; Mg: $26 \mathrm{mmol}_{\mathrm{c}} \cdot \mathrm{dm}^{-3} \cdot \mathrm{V}: 82 \%$. O clima da região é tropical de altitude com verões quentes e chuvosos, apresentando temperatura média anual de $22^{\circ} \mathrm{C}$ e precipitação de $1192 \mathrm{~mm}$.

Trabalhou-se com a cultivar Brasília, recomendada para o plantio de verão na região, semeada diretamente no leito de plantio em 30/09/98 no sentido transversal ao canteiro, sendo que as sementes foram uniformemente distribuídas nos sulcos de plantio espaçados em $20 \mathrm{~cm}$ e a $1,5 \mathrm{~cm}$ de profundidade.

Realizou-se a aplicação de fertilizantes de acordo com a análise do solo e recomendações para o estado de São Paulo (RAIJ et al., 1996). Foram utilizados 20 kg.ha ${ }^{-1}$ de N, 180 kg.ha ${ }^{-1}$ de $\mathrm{P}_{2} \mathrm{O}_{5}$ e 60 kg.ha ${ }^{-1}$ de $\mathrm{K}_{2} \mathrm{O}$. Durante o ciclo cultural foram realizadas três adubações de cobertura com nitrogênio $\left(60 \mathrm{~kg} \cdot \mathrm{ha}^{-1}\right)$ e potássio (40 kg.ha ${ }^{-1}$ ), aos 15 , 30 e 50 dias após a semeadura. Aos 25 dias da semeadura realizou-se o desbaste deixando-se um espaçamento de $5 \mathrm{~cm}$ entre plantas. Os demais tratos culturais foram realizados de acordo com as recomendações técnicas para cultura da cenoura na região.

O delineamento experimental utilizado foi o de blocos casualizados, com cinco tratamentos e quatro repetições. Avaliaram-se os seguintes tipos de cobertura morta: serragem de madeira, casca de arroz, maravalha (raspas da madeira), capim seco Tifton (Cynodon spp.), cortado antes de produzir sementes, além de uma testemunha constituída pelo solo sem cobertura morta. Os canteiros foram mantidos durante todo o ciclo cultural com as coberturas, utilizando-se camadas uniformes, distribuídas de maneira que o solo ficasse totalmente coberto. Cada parcela foi montada com dimensões de 1,0 m de largura por 2,0 m de comprimento, totalizando uma área de 2,0 $\mathrm{m}^{2}$.

Avaliou-se a temperatura do solo por meio de medições semanais com termômetro específico em dois pontos da parcela. As medições foram feitas sempre às 14 horas a uma profundidade de $5 \mathrm{~cm}$ abaixo da superfície do solo.

A umidade foi quantificada pelo método da diferença de peso, coletando-se amostras de solo no centro das parcelas, a $10 \mathrm{~cm}$ de profundidade, acondicionadas em recipientes de isopor e imediatamente pesados (peso inicial). Posteriormente, as amostras eram colocadas em estufas a $105^{\circ} \mathrm{C}$, até a completa secagem do solo e então pesadas (peso final). $\mathrm{O}$ teor de umidade do solo foi obtido e a diferença entre as pesagens final e inicial das amostras, e posteriormente o peso foi transformado em porcentagem.

Realizaram-se avaliações aos 30, 45 e 60 dias após a semeadura do comprimento da folha e número de folhas/planta. A colheita do experimento ocorreu em 05/01/99, aos 97 dias após a semeadura, colhendo-se todas as plantas da área útil da parcela $\left(0,5 \mathrm{~m}^{2}\right)$. Após a colheita determinaram-se o número de plantas colhidas, comprimento e peso médio das raízes e produtividade.

\section{RESULTADOS E DISCUSSÃO}

Os materiais utilizados como cobertura morta na cultura da cenoura foram igualmente eficientes e com resultados significativamente diferentes da ausência de cobertura na manutenção das características de umidade e temperatura do solo (Tabela 1). Em média, esses materiais mantiveram o solo com um gradiente de temperatura de aproximadamente $3,5^{\circ} \mathrm{C}$ inferior ao tratamento sem cobertura e a umidade manteve-se $2,0 \%$ superior ao solo descoberto. A utilização de restos vegetais como 
cobertura morta em outras hortaliças apresentaram resultados semelhantes. Na cultura do alho, o uso de cobertura morta de solo proporcionou temperaturas mais amenas e teores de umidade mais elevados que o polietileno opaco branco e solo nu (COSTA et al., 1997). Da mesma forma, na cultura do taro (Colocasia esculenta), verificou-se que o uso de materiais derivados de madeira e restos vegetais como cobertura de solo associados à adubação orgânica, foram eficientes na manutenção da umidade, resultando em rizomas com maior peso de matéria fresca e seca (MIYASAKA et al., 2001).

Tem sido demonstrado que temperaturas mais amenas resultam em cenouras com raízes de coloração mais intensa e associadas com uma boa disponibilidade e distribuição de água no perfil do solo tem-se raízes mais alongadas, evitando-se deformações (FILGUEIRA, 1982). Nos cultivos de verão, a ocorrência de temperaturas eleva- das associadas ao ressecamento rápido do solo podem comprometer a produção da cenoura. Como vantagem adicional, o impacto de chuvas pesadas, passíveis de ocorrer no verão, na desagregação do solo e na perda de nutrientes são também minimizados pela utilização da cobertura de solo (TRUMAN e WILLIAMS, 2001).

As espécies de plantas daninhas identificadas no experimento foram Portulaca oleracea (beldroega), Bidens pilosa (picão-preto), Eleusine indica (péde-galinha) Amaranthus lividus (caruru), Brachiaria plantaginea (marmelada). Essas espécies foram as mesmas tanto na primeira avaliação (20 dias após a semeadura) como na segunda (45 dias após a semeadura). As maiores densidades de plantas daninhas foram das espécies $P$. oleracea e E. indica, e as de menor densidade foram A. lividus e B. plantaginea (Tabela 2).

TABELA 1 - Médias de temperatura e umidade do solo durante o ciclo da cenoura em função de diferentes tipos cobertura morta de solo. UNIMAR, Marília - SP, 1999.

\begin{tabular}{ccc}
\hline Cobertura do solo & Temperatura ( $\left.{ }^{\mathbf{C}} \mathbf{C}\right)$ & Umidade (\%) \\
\hline Sem cobertura & $31,99 \mathrm{a}$ & $9,79 \mathrm{~b}$ \\
Serragem & $28,53 \mathrm{bc}$ & $12,10 \mathrm{a}$ \\
Casca de arroz & $28,80 \mathrm{~b}$ & $12,16 \mathrm{a}$ \\
Maravalha & $28,27 \mathrm{c}$ & $11,41 \mathrm{a}$ \\
Capim seco & $28,84 \mathrm{~b}$ & $11,72 \mathrm{a}$ \\
\hline C.V. (\%) & 1,11 & 7,82 \\
\hline
\end{tabular}

Médias seguidas pelas mesmas letras nas colunas não diferem entre si, pelo teste de Duncan, a 5\% de probabilidade.

TABELA 2 - Ocorrência de espécies e quantidade de plantas daninhas (número de plantas/m²) na cultura da cenoura em função dos tipos de cobertura morta de solo, 20 e 45 dias após a semeadura (DAS). UNIMAR, Marília - SP, 1999.

\begin{tabular}{|c|c|c|c|c|c|c|}
\hline \multicolumn{7}{|c|}{ Incidência de plantas daninhas $\left(n^{\circ}\right.$ plantas $\left./ m^{2}\right)$ - 20 DAS } \\
\hline Cobertura do solo & $\begin{array}{c}\text { Portulaca } \\
\text { oleracea }\end{array}$ & $\begin{array}{c}\text { Bidens } \\
\text { pilosa }\end{array}$ & $\begin{array}{c}\text { Eleusine } \\
\text { indica }\end{array}$ & $\begin{array}{c}\text { Amaranthus } \\
\text { lividus }\end{array}$ & $\begin{array}{c}\text { Brachiaria } \\
\text { plantaginea }\end{array}$ & Total \\
\hline Sem cobertura & 52,75 a & $10,50 \mathrm{a}$ & $25,00 \mathrm{a}$ & $1,00 \mathrm{a}$ & $1,00 \mathrm{a}$ & 90,25 a \\
\hline Serragem & $12,75 \mathrm{~b}$ & 5,75 a & $6,25 \mathrm{~b}$ & $0,75 \mathrm{a}$ & 0,00 a & $25,50 \mathrm{bc}$ \\
\hline Casca de arroz & $10,75 \mathrm{~b}$ & 9,25 a & 26,25 a & $0,00 \mathrm{a}$ & 0,25 a & $46,50 \mathrm{~b}$ \\
\hline Maravalha & $2,25 \mathrm{~b}$ & 5,50 a & $5,75 \mathrm{~b}$ & $0,00 \mathrm{a}$ & 0,25 a & $13,75 \mathrm{c}$ \\
\hline Capim seco & $3,75 \mathrm{~b}$ & 7,50 a & $1,50 \mathrm{~b}$ & $0,00 \mathrm{a}$ & $0,25 \mathrm{a}$ & $13,00 \mathrm{c}$ \\
\hline \multicolumn{7}{|c|}{ Incidência de plantas daninhas $\left(n^{\circ}\right.$ plantas $\left./ \mathrm{m}^{2}\right)$ - 45 DAS } \\
\hline Sem cobertura & 30,50 a & 4,75 bc & $12,25 \mathrm{a}$ & $0,00 \mathrm{~b}$ & $1,25 \mathrm{a}$ & 48,75 a \\
\hline Serragem & $10,25 \mathrm{~b}$ & $5,50 \mathrm{ab}$ & $9,50 \mathrm{ab}$ & $0,00 \mathrm{~b}$ & 0,25 a & $25,50 \mathrm{~b}$ \\
\hline Casca de arroz & $7,75 \mathrm{~b}$ & 7,75 a & 4,75 bc & $1,50 \mathrm{a}$ & $1,50 \mathrm{a}$ & 23,25 bc \\
\hline Maravalha & $8,00 \mathrm{~b}$ & 3,00 bc & 3,00 bc & $0,00 \mathrm{~b}$ & $0,00 \mathrm{a}$ & $14,00 \mathrm{bc}$ \\
\hline Capim seco & $6,00 \mathrm{~b}$ & $2,25 \mathrm{c}$ & $2,50 \mathrm{c}$ & $0,50 \mathrm{ab}$ & $0,00 \mathrm{a}$ & $11,25 \mathrm{c}$ \\
\hline
\end{tabular}

*Médias seguidas pelas mesmas letras colunas não diferem entre si, pelo teste de Duncan, a $5 \%$ de probabilidade.

Ciênc. agrotec., Lavras, v. 29, n. 1, p. 100-105, jan./fev. 2005 
Todas as coberturas mortas estudadas reduziram significativamente o número total de plantas daninhas em relação ao solo descoberto nas duas avaliações (Tabela 2). Sabe-se que o uso de cobertura morta de solo tem ampla ação sobre plantas daninhas, cujas sementes exigem luz (SILVA, 1970) ou variação térmica (OLIVEIRA, 1985) para germinação, permitindo manter a cultura de interesse sem competição durante parte de seu ciclo.

As coberturas de solo apresentaram um controle efetivo de $P$. oleracea em ambas as avaliações. As coberturas com capim seco e maravalha foram as que mais reduziram a germinação de plantas da espécie $E$. indica; enquanto para A. lividus e B. plantaginea o uso de cobertura de solo não se mostrou eficiente no controle de plantas destas espécies.

A altura e o número de folhas da cenoura mostraram valores diferenciados em função do material utilizado como cobertura do solo, nas três épocas em que estas características foram avaliadas. O solo coberto com casca de arroz e maravalha proporcionou maior altura de plantas aos 30 e 45 dias após a semeadura, seguidos pela serragem e capim seco (Figura 1). Aos 60 dias, o efeito dos tipos de coberturas sobre a altura da planta foi semelhante entre os tratamentos, provavelmente em função da parte aérea das plantas já estar cobrindo completamente o solo. O desempenho observado para altura de planta no solo sem cobertura foi significativamente inferior a todos os demais tratamentos, nas três épocas de avaliação.

$O$ efeito mais significativo das coberturas de solo sobre o número de folhas foi verificado aos 30 dias da semeadura, quando a utilização da maravalha e casca de arroz mostraram influência significativamente superior ao capim seco e em relação ao solo descoberto. Aos 45 e 60 dias, o número de folhas mostrou-se pouco variável, principalmente dos tipos e cobertura morta em relação ao solo descoberto (Figura 1).

Todas as características ligadas à produção foram significativamente influenciadas pela cobertura de solo, com exceção do comprimento da raiz (Tabela 3).

De acordo com o número de plantas colhidas, verificou-se que as coberturas com casca de arroz, maravalha e serragem proporcionaram maior sobrevivência de plantas de cenoura em relação ao capim seco e ao solo descoberto (Tabela 3). O comprimento da raiz não foi influenciado pelos diferentes tipos de cobertura de solo e pela ausência ou presença de cobertura morta. Essa característica tem mais relação com a distribuição de água e nutrientes no perfil do solo, embora, temperaturas amenas contribuam também para o crescimento longitudinal de raízes na cultura da cenoura (FILGUEIRA, 1982).

Para o peso médio de raiz sobressaíram-se as coberturas com casca de arroz e capim seco, este último em função do estande mais baixo que ocasionou menor competição entre as plantas e portanto, raízes relativamente maiores e mais pesadas. Entretanto, este aspecto não se refletiu na produtividade, sendo que a casca de arroz destacou-se influenciando mais efetivamente esta característica, aparecendo em seguida a maravalha. A utilização de cobertura de solo com materiais sintéticos ou naturais tem apresentado bons resultados em hortaliças, entretanto, após três anos, Feldman et al. (2000) verificaram em repolho e melão que o uso de compostos naturais além de proporcionar maior produtividade, são de custo mais baixo que os sintéticos.

Os materiais testados como cobertura de solo neste trabalho são encontrados com relativa facilidade nas várias regiões do país, podendo sua utilização ser viável economicamente para cultura da cenoura em pequenas áreas e em cultivos orgânicos. 

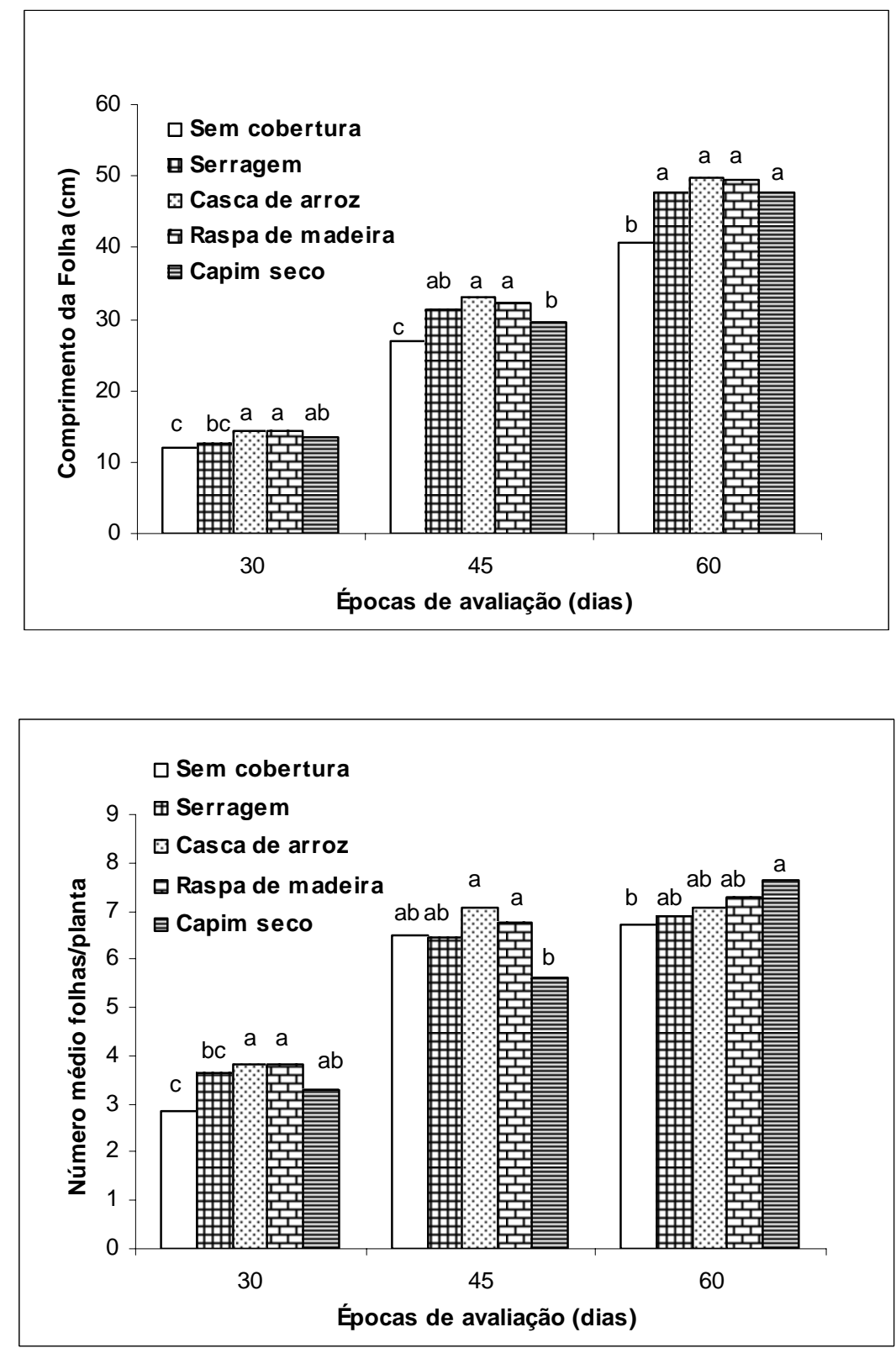

FIGURA 1 - Altura de plantas e número médio de folhas de cenoura cultivada com diferentes tipos de cobertura morta de solo, em três épocas de avaliação após a semeadura.UNIMAR, Marília - SP, 1999. (Barras seguidas de mesma letra dentro das épocas de avaliação não diferem entre si a 5\% de probabilidade pelo teste Duncan). 
TABELA 3 - Número de plantas $/ \mathrm{m}^{2}$, comprimento e peso médio de raiz, produtividade total da cenoura cultivada com diferentes tipos de cobertura morta de solo UNIMAR, Marília - SP, 1999.

\begin{tabular}{|c|c|c|c|c|}
\hline Cobertura do solo & № plantas $/ \mathbf{m}^{2}$ & $\begin{array}{l}\text { Comprimento da } \\
\text { raiz }(\mathrm{cm})\end{array}$ & $\begin{array}{l}\text { Peso médio de raiz } \\
\text { (g) }\end{array}$ & $\begin{array}{c}\text { Produtividade } \\
\text { total }\left(\text { t.ha }{ }^{-1}\right)\end{array}$ \\
\hline Sem cobertura & 74,66 b & 16,95 a & 66,93 bc & $64,60 \mathrm{~b}$ \\
\hline Serragem & $131,50 \mathrm{a}$ & 15,36 a & $63,44 \mathrm{c}$ & $83,80 \mathrm{ab}$ \\
\hline Casca de arroz & 124,50 a & $15,70 \mathrm{a}$ & $81,42 \mathrm{ab}$ & $112,60 \mathrm{a}$ \\
\hline Maravalha & 138,50 a & $17,02 \mathrm{a}$ & 42,13 bc & 99,60 a \\
\hline Capim seco & $94,50 \mathrm{~b}$ & 17,07 a & 90,26 a & $84,20 \mathrm{ab}$ \\
\hline C.V. (\%) & 13,25 & 8,78 & 12,95 & 22,48 \\
\hline
\end{tabular}

Médias seguidas por letras iguais nas colunas não diferem entre si (Duncan, 5\%).

\section{CONCLUSÕES}

A utilização da cobertura morta de solo constituise numa prática vantajosa para o cultivo de verão da cenoura, melhorando as características hidrotérmicas do solo, reduzindo a incidência de plantas invasoras, estimulando o desenvolvimento das plantas e aumentando a produtividade em relação ao solo descoberto.

Entre os tipos de cobertura morta utilizados, a casca de arroz e a maravalha se destacaram em relação ao solo descoberto como os materiais que proporcionaram maior produtividade para cultura da cenoura.

\section{REFERÊNCIAS BIBLIOGRÁFICAS}

BLANCO, H. G.; OLIVEIRA, D. O. Duração do período de competição das plantas daninhas. O Biológico, São Paulo, v. 37, p. 3-7, 1971.

COSTA, J. T. A.; SILVA, L. A. da; MELO, F. I. O. Efeitos do turno de rega e cobertura morta na cultura do alho na serra da Ibiapaba, Ceará: I. umidade e temperatura do solo. Ciência Agronômica, Fortaleza, v. 28, n. 1/2, p. 70-84, 1997.

FELDMAN, R. S.; HOLMES, C. E.; BLOMGREN, T. A. Use of fabric and compost mulches for vegetables production in low tillage, permanent bed system: effects on crop yield and labor. American Journal of Alternative Agriculture, Greenbelt, v. 15, n. 3, p. 146-153, 2000.

FILGUEIRA, F. A. R. Manual de olericultura: cultura e comercialização de hortaliças. São Paulo: Agronômica Ceres, 1982. v. 2, 357 p.
MIYASAKA, S. C.; HOLLYER, J. R.; KODANI, L. S. Mulch and compost effects on yield and corm rots of taro. Field Crops Research, Amsterdam, v. 71, n. 2, p. 101-112, 2001.

MULLER, A. G. Comportamento térmico do solo e do ar em alface (Lactuca sativa L.) para diferentes tipos de cobertura do solo. 1991. 77 f. Dissertação (Mestrado) - Escola Superior de Agricultura Luiz de Queiroz, Piracicaba, 1991.

OLIVEIRA, A. P. de. Efeito de bagaço de cana-deaçúcar associado à adubação nitrogenada sobre a produção dos alho (Allium sativum L.) Amarante e Dourados. 1985. 51 f. Dissertação (Mestrado) - Universidade Federal de Viçosa, Viçosa, 1985.

PEREIRA, C. Z.; DOMINGOS, S. R.; GOTO, R. Cultivo de alface tipo americana no verão, com diferentes tipos de solo. Horticultura Brasileira, Brasília, v. 18, p. 491-492, jul. 2000. Suplemento.

RAIJ, B. V. et al. Recomendações de calagem e adubação para o Estado de São Paulo. Campinas: IAC, 1996. 285 p.

SILVA, J. F. Herbicidas e ervas daninhas. Viçosa: UFV, 1970. 107 p.

TRUMAN, C. C.; WILLIAMS, R. G. Effects of peanut cropping and canopy cover conditions on runoff and sediment yield. Journal of Soil and Water Conservation, Ankeny, v. 56, n. 2, p. 152-159, 2001.

WILLIAM, R. D.; WARRE, G. F. Competion between purple nut redge and vegetables. Weed Science, Champaign, v. 23, n. 4, p. 317-23, 1975. 
